\title{
Selected psychological factors and medication adherence in patients with rheumatoid arthritis
}

\author{
Monika Bąk-Sosnowska ID , Julia Wyszomirska ID , Anna Daniel-Sielańczyk ID \\ Department of Psychology, Medical University of Silesia, Katowice, Poland
}

\begin{abstract}
Objectives: The aim of the study was to determine the relationship between medication adherence (MA) and selected psychological factors in a group of patients with rheumatoid arthritis (RA). Material and methods: The cross-sectional study was conducted in four rheumatology outpatient clinics in Silesia, Poland. The tests used were the Medication Adherence Questionnaire (MAQ), the Multidimensional Health Locus of Control Scale (MHLC), the Coping Inventory for Stressful Situations (CISS), and the Mindful Attention Awareness Scale (MAAS). The analysis involved 106 adult patients diagnosed with RA at least 6 months before, who were prescribed medication, with disease at any stage and with stable comorbidities. Software was used to perform analyses of frequency, basic descriptive statistics, including the Kolmogorov-Smirnov test, Student's $t$-test for independent samples, intergroup univariate variance, Pearson's $r$ correlation coefficient, Spearman's rank correlation $\rho$ coefficient, Fisher's exact test and stepwise linear regression.

Results: Powerful Others Health Locus of Control (PHLC), Internal Health Locus of Control (IHLC) and age of the subjects, $F(3,102)=8.05 ; p<0.001$ explained $16.8 \%$ of the variation in the adherence level for the entire group. In the group of women PHLC and IHLC, $F(2,80)=10.04 ; p<0.001$ were included in the model, which explained $18.1 \%$ of variation in MA. PHLC was the most significant factor in the group of women $(\beta=0.55 ; p<0.001)$ and in the entire group $(\beta=0.48 ; p<0.001)$. In the group of men, Social Diversion Style (SDS), $F(1,21)=5.81 ; p=0.02$ was included in the model, which explained $17.9 \%$ of the variation in the MA level.

Conclusions: The study identified some psychological predictors of adherence, which explained $16.8 \%$ of the variability. Factors increasing the likelihood of medication adherence in patients with rheumatoid arthritis include a strong belief in the power of others, low level of internal health locus of control, and advanced age.
\end{abstract}

Key words: rheumatoid arthritis, psychological factors, medical adherence.

\section{Introduction}

Rheumatoid arthritis (RA) is an autoimmune disease characterised by non-specific inflammation of symmetrical joints. It leads to chronic pain, fatigue, increased risk of cardiovascular diseases, infection and premature death [1-3].

The disease limits physical function, which may result in severe disability, and adversely affects the emotional, interpersonal and professional domains, reducing the quality of patients' lives [4, 5].
The global age-standardised prevalence rate of RA is 246.6/100 000, which increased by $7.4 \%$ between 1990 and 2017 . The global age-standardised incidence rate of RA is 14.9 , an increase of $8.2 \%$ in the same period.

The Global Burden of Diseases, Injuries, and Risk Factors study (GBD), 2017 showed that age-standardised prevalence and disability adjusted life years (DALYs) rates were higher in females and increased with age, peaking in the 70-74 and 75-79 age groups among females and males, respectively [6].

Address for correspondence:

Anna Daniel-Sielańczyk, Department of Psychology, Medical University of Silesia, Katowice, 12 Medyków St., 40-752 Katowice, Poland, e-mail: adanielsielanczyk@sum.edu.pl, ORCID: https://orcid.org/0000-0002-0152-6982

Submitted: 27.01.2021; Accepted: 06.04.2021 
In Poland, the general incidence is $0.9 \%$, being $1.06 \%$ in women and $0.74 \%$ in men. The mean age of onset is 56 years, and in over a half (56\%) of newly diagnosed patients the disease activity is high [7].

Present European League Against Rheumatism (EULAR) guidelines recommend using fast-acting analgesic and anti-inflammatory medications, i.e. non-steroidal antiinflammatory drugs (NSAIDs), steroids, and slow-acting second-line therapies, i.e. synthetic or biological disease modifying anti-rheumatic drugs (DMARDs), to slow down the progression of RA [8].

In Poland, $80 \%$ of patients receive methotrexate as the first-line therapy, and biological drugs are used only by $2.94 \%$ of patients. The goal of pharmacotherapy is to achieve long-term (at least 6 months) remission or low disease activity. It requires regular and frequent, especially at the initial stages of treatment, visits to the rheumatologist, and adherence to medical advice [7, 9].

Insufficient adherence, estimated at $30-80 \%$, is a significant problem in RA patients [10]. Studies indicate that it is a complex issue, determined by environmental factors (e.g. low income, living in the country), health status (e.g. comorbidities, multiple diseases), and by the treatment (e.g. polypharmacotherapy, insufficient knowledge about the disease management, lack of remission, fear of adverse effects, drug accessibility) [11].

The effect of psychological factors, such as lack of motivation, poor quality of patient-doctor relationship, low level of self-efficacy, low level or conscientiousness or social support, has also been demonstrated $[12,13]$.

Analysis of the literature indicates that medication adherence is determined by other psychological variables as well. The metanalysis conducted by Náfrádi et al. [14] demonstrated that Health Locus of Control (HLOC) is an important factor affecting medication adherence.

Health Locus of Control is defined as a belief that one has influence on one's health and self-determination (internal HLOC), or that external factors, such as Powerful others, Doctor, God, or Chance play the major role (external HLOC). It has been demonstrated that internal HLOC has a positive effect on medication adherence, whereas external HLOC has a negative or ambiguous effect, except for Locus of Control Doctor Health, which demonstrates a positive relationship.

Health locus of control is commonly used as a predictor of health-related behaviour; however, no studies examining the relationship between HLOC and medication adherence in RA patients have been found in the PubMed database for the years 2000-2020.

Since disease, especially a chronic one, is a stressful situation, patient's functioning is also determined by the style of coping with stress, understood as a combination of cognitive and behavioural efforts to control, reduce or eliminate stress [15]. Studies exploring the relationships between coping strategies and medication adherence are not extensive. For instance, such a study was conducted in a group of oncological patients [16]. However, no reports analysing this relationship in RA patients have been found.

In the past years, many researchers have focused on mindfulness and its association with health. Mindfulness is defined as an intentional, non-judgemental attention to the present moment [17]. The available studies indicate a positive relationship between mindfulness and medication adherence, e.g. in patients with HIV [18] or schizophrenia [19]. No reports regarding this type of relationship in RA patients have been found in the PubMed database.

Therefore, the aim of our study was to determine the relationship between medication adherence and the locus of health control, style of coping with stress, and level of mindfulness in the group of patients with RA.

Those psychological factors were related with health and present varying levels of stability. The most modifiable is mindful attention (MA) [20]. The most stable is stress coping (SC), which is defined as a response to a specific situation, and is a relatively permanent, individual choice of how to respond to a difficult situation in a particular way $[15,21]$. Health Locus of Control $(\mathrm{HLC})$ is characterized by medium level of stability [22].

\section{Material and methods \\ Study design}

The cross-sectional study was conducted from October and December 2018, in four rheumatology outpatient clinics in Silesia, Poland. All the patients who came to planned visits in the study period, and met the inclusion criteria, were invited to participate. Participation in the study was voluntary and anonymous.

The time to answer the questions in the survey questionnaire was unlimited. Subjects completed questionnaires independently, while waiting for the visit. They did not receive payment for the participation in the study. The completed questionnaires were submitted in a special box in the clinic's reception.

The data collected in the study were entered into an Excel database and analysed using IBM SPSS Statistics 23. The software was used to perform analyses of frequency, basic descriptive statistics, including the Kolmogorov-Smirnov test, Student's t-test for independent samples, intergroup univariate variance, Pearson's $r$ correlation coefficient, Spearman's rank correlation $\rho$ coefficient, Fisher's exact test and stepwise linear regression.

As in all the variables the distribution was normal, or a minor asymmetry of distribution relative to the mean 
Table I. Sociodemographic data

\begin{tabular}{|c|c|c|}
\hline Variable & Number of patients & Percent (\%) \\
\hline \multicolumn{3}{|l|}{ Gender } \\
\hline Female & 83 & 78.3 \\
\hline Male & 23 & 21.7 \\
\hline \multicolumn{3}{|l|}{ Place of residence } \\
\hline Urban & 58 & 54.7 \\
\hline Rural & 48 & 45.3 \\
\hline \multicolumn{3}{|l|}{ Education } \\
\hline Primary school & 18 & 17 \\
\hline Vocational school & 50 & 47.2 \\
\hline Secondary school & 20 & 18.9 \\
\hline Higher education & 18 & 17 \\
\hline \multicolumn{3}{|l|}{ Employment } \\
\hline In work & 49 & 46.2 \\
\hline Out of work & 57 & 53.8 \\
\hline \multicolumn{3}{|l|}{ Marital status } \\
\hline Single & 7 & 6.6 \\
\hline Divorced & 7 & 6.6 \\
\hline Widowed & 14 & 13.2 \\
\hline Married & 69 & 65.1 \\
\hline Cohabitant & 9 & 8.5 \\
\hline \multicolumn{3}{|l|}{ Number of children } \\
\hline 0 & 13 & 12.3 \\
\hline 1 & 23 & 21.7 \\
\hline 2 & 39 & 36.8 \\
\hline$\geq 3$ & 31 & 29.2 \\
\hline \multicolumn{3}{|l|}{ Faith } \\
\hline Non-believer & 8 & 7.5 \\
\hline Believer & 98 & 92.5 \\
\hline
\end{tabular}

were observed (the bias values ranged from -2 to +2 ), the statistical analyses were conducted using parametric tests, in compliance with other conditions. A standard significance level of $\alpha=0.05$ was adopted.

The study was approved by the relevant Bioethical Committee (approval no. KNW/0022/KB/170/17). The authors designed and conducted the study in compliance with the applicable provisions of law, including the requirements regarding personal data protection, respect for patient's rights, and ethical guidelines of the Declaration of Helsinki.

\section{Participants}

The following inclusion criteria were adopted: diagnosis of RA determined at least 6 months prior to the study, stable course of comorbidities, outpatient treatment during the study, age over 18 years old. Patients at any disease stage were included, and regardless of the disease duration, provided it was over 6 months.

The inclusion criteria were as follows: no prescription for constant medication in the three months preceding the study, and limited independence regarding control and administration of medications (serious mental disability, serious mental illness). Eventually, the study involved 106 patients, including 83 women (78.3\%) and 23 men (21.7\%). The subjects were aged 30 to 79 $(M=57.55 ; S D=9.57)$. A majority of subjects were in stable relationships, had at least one child, and were religious. No significant differences were observed regarding other demographic characteristics (Table I).

\section{Measures}

Diagnostic survey using questionnaires was used. Most questionnaires were standardised.

For self-reported medication adherence, the Medication Adherence Questionnaire (MAQ) was used [22]. The Medication Adherence Questionnaire is a popular tool for measuring adherence, and it was validated using a varied population of patients $[23,24]$. It includes four questions: 1. Do you ever forget to take your medicine?

2. Are you careless at times about taking your medicine? 3. When you feel better do you sometimes stop taking your medicine?

4. Sometimes if you feel worse when you take the medicine, do you stop taking it?

Some authors distinguish two MAQ subscales: regarding unintentional nonadherence (UN) (questions 1, 2), and intentional nonadherence (IN) (questions 3, 4) [24].

In the MAQ patients can score 0 to 4 points. The response to all questions is "yes" or "no". To assess the level of adherence, each negative response receives one point, and no points are given for positive responses. Similarly to studies by other authors, three levels of adherence were distinguished: high, moderate, and low [22]. For research purposes, low (0-1), medium (2-3) and high (4) adherence levels can be distinguished [25].

To assess the health locus of control, the Multidimensional Health Locus of Control Scale (MHLC) in the Polish adaptation was used $[22,26]$. The MHLC questionnaire comprises 18 statements related to beliefs regarding the generalised expectations associated with three dimensions of the health locus of control: Internal Health Locus of Control (IHLC) - I am in control of my health; Powerful others Health Locus of Control (PHLC) - my health is a result of the actions of others, especially medical personnel; Chance Health Locus of Control (CHLC) - my health is determined by chance or other external factors. A subject responds to presented statements by declaring to what degree he or she agrees with the statement, from 1 - I completely disagree to 
Table II. Basic descriptive statistics of the analysed quantitative variables

\begin{tabular}{lccccccccc}
\hline & M & Me & SD & Sk. & Kurt. & Min & Max & K-S & $p$ \\
\hline Medication adherence (MA) & 2.04 & 2 & 0.94 & -0.08 & 0.03 & 0 & 4 & 0.24 & $<0.001$ \\
\hline Unintentional nonadherence (UN) & 1.17 & 1 & 0.68 & -0.23 & -0.84 & 0 & 2 & 0.27 & $<0.001$ \\
\hline Intentional nonadherence (IN) & 0.79 & 1 & 0.81 & 0.40 & -1.38 & 0 & 2 & 0.29 & $<0.001$ \\
\hline Internal Health Locus of Control (IHLC) & 21.24 & 21 & 3.36 & 0.73 & 0.05 & 16 & 30 & 0.13 & $<0.001$ \\
\hline Powerful others Health Locus of Control (PHLC) & 23.10 & 22 & 3.28 & 0.55 & 1.18 & 15 & 34 & 0.17 & $<0.001$ \\
\hline Chance Health Locus of Control (CHLC) & 26.16 & 27 & 3.22 & -1.49 & 4.09 & 11 & 31 & 0.17 & $<0.001$ \\
\hline Task-Oriented Style (TOS) & 47.96 & 49 & 6.55 & -0.37 & 0.60 & 33 & 64 & 0.12 & 0.001 \\
\hline Emotion-Oriented Style (EOS) & 44.93 & 46 & 8.33 & 0.16 & -0.13 & 28 & 72 & 0.09 & 0.040 \\
\hline Avoidance-Oriented Style (AOS) & 46.48 & 47 & 6.40 & -0.07 & 0.14 & 30 & 63 & 0.08 & 0.060 \\
\hline Distraction Style (DS) & 22.14 & 22.5 & 4.14 & -0.07 & 0.07 & 11 & 35 & 0.13 & $<0.001$ \\
\hline Social Diversion Style (SDS) & 15.53 & 16 & 2.67 & -0.25 & -0.25 & 9 & 21 & 0.12 & $<0.001$ \\
\hline Mindfulness (M) & 47.39 & 45.5 & 9.57 & 1.44 & 3.16 & 30 & 79 & 0.18 & $<0.001$ \\
\hline Age [years] & 57.55 & 58 & 11.37 & 0.10 & -0.47 & 33 & 82 & 0.06 & 0.200 \\
\hline BMI [kg/m ${ }^{2}$ ) & 25.49 & 25.77 & 3.89 & 0.41 & -0.42 & 18.21 & 35.32 & 0.07 & 0.200 \\
\hline KS Kolmogoro-Smimov testresut Kut
\end{tabular}

K-S - Kolmogorov-Smirnov test result, Kurt. - kurtosis, M - mean, Me - median, Min and Max - the lowest and highest distribution value, SD - standard deviation, Sk. - skewness, $p$ - significance.

6 - I completely agree; 6 to 36 points can be scored in each dimension. A high score in a given scale indicates a strong belief in its effect on one's health.

The style of coping with stress was examined using a Polish adaptation of the Coping Inventory for Stressful Situations (CISS) [15, 27]. The Coping Inventory for Stressful Situations comprises 48 items to which the subject responds by marking the frequency of a reaction to a stressful situation on a 5-point scale, where $1=$ never, 2 = very rarely, $3=$ sometimes, $4=$ often, and $5=$ very often.

Three coping strategies are distinguished in the questionnaire: Task-Oriented Style (TOS), EmotionOriented Style (EOS), and Avoidance-Oriented Style (AOS), divided into engagement in substitute activities - Distraction Style (DS) - and seeking social interaction - Social Diversion Style (SDS).

The level of mindfulness (M) was assessed using the Polish version of Mindful Attention Awareness Scale (MAAS) [20, 28]. The Mindful Attention Awareness Scale is used to examine a disposition for mindfulness. The questionnaire consists of 15 statements that describe daily experiences regarding mindfulness. The subject is to assess the frequency of experiencing them on a 6-point scale, where 1 means 'almost always' and 6 'almost never'. The overall score obtained in the test ranges from 15 to 90 points. The higher the score, the higher the level of mindfulness.

The sociodemographic data were collected using our questionnaire, which included age, gender, place of residence, education, professional activity, relationship status, children, and attitude to religious faith.

\section{Results}

Table II presents the basic descriptive statistics of the analysed variables and their distribution.

The medication adherence level of the subjects is presented in the histogram below (Fig. 1). The results are divided into three groups: low scores (24.5\%), moderate scores (69.8\%) and high scores (5.7\%).

Contribution of various MAQ factors to the general level of MA was analysed. A higher correlation between a subscale result and the general score was found for intentional nonadherence $(r=-0.703 ; p<0.001)$, compared to unintentional nonadherence $(r=-0.532 ; p<0.001)$.

Since the study group significantly varied regarding the gender variable, the effect of the gender variable on the MAQ score was examined. No difference was observed between women and men regarding the general MA level. Men scored higher in the UN subscale, whereas women

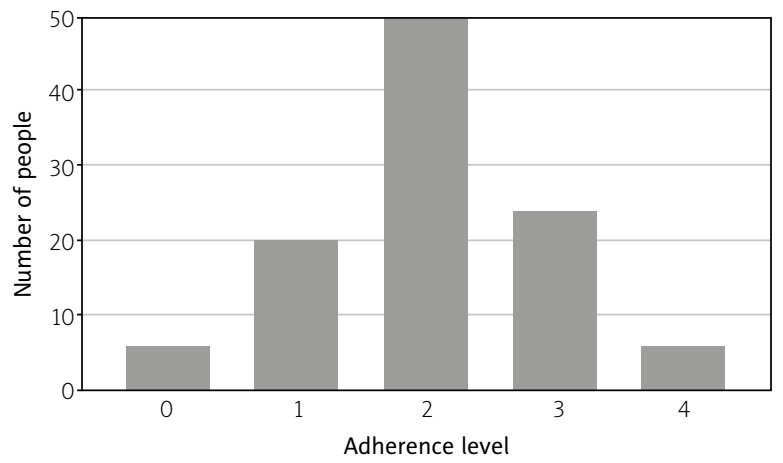

Fig. 1. Adherence level of the studied group. 
Table III. Adherence level depending on gender

\begin{tabular}{|c|c|c|c|c|c|c|c|c|c|}
\hline & \multicolumn{2}{|c|}{ Female $(n=83)$} & \multicolumn{2}{|c|}{ Male $(n=23)$} & \multirow[t]{2}{*}{$t$} & \multirow[t]{2}{*}{$p$} & \multicolumn{2}{|c|}{$95 \% \mathrm{Cl}$} & \multirow[t]{2}{*}{ Cohen's $d$} \\
\hline & M & SD & M & SD & & & LL & UL & \\
\hline Medication adherence (MA) & 2.02 & 0.99 & 2.09 & 0.73 & -0.28 & 0.77 & -0.50 & 0.38 & 0.07 \\
\hline Unintentional nonadherence (UN) & 1.08 & 0.67 & 1.48 & 0.67 & -2.51 & 0.01 & -0.71 & -0.08 & 0.60 \\
\hline Intentional nonadherence (IN) & 0.89 & 0.86 & 0.43 & 0.51 & 3.23 & 0.002 & 0.17 & 0.74 & 0.58 \\
\hline
\end{tabular}

$C I$ - confidence interval, $L L$ - lower limit, $M$ - mean, SD - standard deviation, $t$ - Student's t test result, UL - upper limit, $p$ - statistical significance.

Table IV. Results of the regression analysis for adherence level

\begin{tabular}{|lccccc|}
\hline & B & SE & $\beta$ & $t$ & $p$ \\
\hline (Constant) & -0.57 & 0.74 & - & -0.78 & 0.43 \\
\hline $\begin{array}{l}\text { Powerful others } \\
\text { Health Locus of } \\
\text { Control (PHLC) }\end{array}$ & 0.14 & 0.03 & 0.48 & 4.40 & $<0.001$ \\
\hline $\begin{array}{l}\text { Internal Health } \\
\text { Locus of Control } \\
\text { (IHLC) }\end{array}$ & -0.07 & 0.03 & -0.25 & -2.30 & 0.02 \\
\hline Age & 0.02 & 0.01 & 0.20 & 2.23 & 0.02 \\
\hline
\end{tabular}

Table V. Results of the regression analysis for adherence level in the group of women and men

\begin{tabular}{|c|c|c|c|c|c|}
\hline & B & SE & $\beta$ & $t$ & $p$ \\
\hline \multicolumn{6}{|l|}{ Women } \\
\hline (Constant) & 0.38 & 0.72 & & 0.52 & 0.60 \\
\hline $\begin{array}{l}\text { Powerful others } \\
\text { Health Locus of } \\
\text { Control (PHLC) }\end{array}$ & 0.16 & 0.04 & 0.55 & 4.48 & $<0.001$ \\
\hline $\begin{array}{l}\text { Internal Health } \\
\text { Locus of Control } \\
(\text { IHLC) }\end{array}$ & -0.09 & 0.04 & -0.32 & -2.62 & 0.010 \\
\hline \multicolumn{6}{|l|}{ Men } \\
\hline (Constant) & -1.26 & 1.40 & & -0.90 & 0.37 \\
\hline $\begin{array}{l}\text { Social Diversion } \\
\text { Style (SDS) }\end{array}$ & 0.21 & 0.09 & 0.47 & 2.41 & 0.02 \\
\hline
\end{tabular}

had higher scores in the IN subscale. The power of both effects was moderately high. Details are presented in Table III.

As for other differences between gender, only one variation was observed: EOS - higher scores were obtained by men $(t=-5.65 ; p<0.001)$.

To examine the relationships between the health locus of control, styles of coping with stress, mindfulness and medication adherence, a series of correlation analyses with Pearson's $r$ coefficient was performed. The Powerful others Health Locus of Control level demonstrated a positive correlation with the MA level $(r=0.33 ; p<0.001)$, and a negative correlation with IN ( $p=-0.406 ; p<0.001)$. The Emotion-Oriented Style level demonstrated a negative correlation with IN $(p=-0.405 ; p<0.001)$, and a positive correlation with
UN ( $p=0.261 ; p<0.01)$. The other relationships were not significant.

In the group of women, IN demonstrated a negative correlation with PHLC (Pearson's $r=-0.451 ; p<0.001$ ), EOS (Pearson's $r=-0.377 ; p<0.001$ ) and DS (Pearson's $r=-0.228 ; p=0.038$ ).

The relationships between demographic characteristics and MA were mostly statistically insignificant. Only the age of subjects correlated positively with MA $(r=0.194 ; p=0.046)$.

To determine predictors of MA, three stepwise linear regression analyses were conducted: for the entire study group, and for men and women separately. Only the psychological variables that were statistically significant predictors of the studied variable were included in the model. For the entire group, three variables were included: level of PHLC, IHLC and age of the subjects, $F(3,102)=8.05 ; p<0.001$. This model explained $16.8 \%$ of the variation in the adherence level. The highest rate of variation was explained by the level of PHLC. The results are summarised in Table IV.

In the group of women, two variables were included in the model: PHLC and IHLC, $F(2,80)=10.04 ; p<0.001$. This model explains $18.1 \%$ of variation in MA, with PHLC being the most significant factor.

In the group of men, only one variable was included in the model: SD, $F(1,21)=5.81 ; p=0.025$. This model explained $17.9 \%$ of the variation in the MA level. The results are presented in Table V.

\section{Discussion}

Adherence to medical advice, especially regarding pharmacotherapy, is of key importance for treatment effectiveness. In acute conditions intensive symptoms and high motivation for recovery are strong motivators to adherence. However, in chronic diseases patients may experience weariness with routine, conflicting emotions regarding the treatment and the fear of adverse effects of long-term medication.

Brandstetter et al. [29] demonstrated that at every stage of the disease, even years after they started pharmacotherapy, RA patients may still negotiate internally the importance of the prescribed pharmacotherapy. 
Each modification of the medical regimen may intensify or trigger this negotiation process. This finding supports the view that medication adherence is a dynamic and changing phenomenon.

In our study we demonstrated that only $5.7 \%$ of RA patients use medication exactly as prescribed. This result is difficult to compare with the results of studies conducted in other countries in the same group of patients, due to variability of measuring tools and different categorisation of the results regarding the studied variable (two, three or four categories). For instance, in a Brazilian study the level of medication adherence in RA patients was $16.4 \%$ [30], in a Dutch study the MA level was 60\% [10], and in a Romanian study it was $60.34 \%$ for the conventional therapy, and $81.30 \%$ for the biological therapy [31].

Our study demonstrated that nonadherence in RA patients was in most cases intentional. Intentional nonadherence is a deliberate behaviour, largely associated with patient's motivation. Unintentional nonadherence, on the other hand, results from inability, or lack of resources for medication [32].

In the present study we did not ask about the reasons of nonadherence; however, we may assume that one of the reasons for intentional patient non-compliance is too weak therapeutic relationship with the physician, especially in the group of women. This hypothesis is supported by the results of regression analysis which indicate that Powerful others (e.g. a physician) can be the main predictor of medication adherence.

Kumar et al. [33] compared RA patients who adhered to medical advice with those who did not. They demonstrated that patients' beliefs about medicines, perceptions about RA, and level of satisfaction with information about DMARDs influenced their adherence to DMARDs.

Patients with a high medical adherence level also indicated the factors that, in their opinion, increased their engagement in therapeutic collaboration, and thus improved their medication adherence. They included good relationships with healthcare professionals, effective communication with the physician regarding the causes of the disease and effects of taking or not taking medications, as well as access to patient support groups [33].

The "Health at a Glance" report, conducted regularly by the Organisation for Economic Co-operation and Development [34], demonstrates that in Poland the time spent by physicians on consultations with patients is much shorter than in other countries (60 patients out of 100 are satisfied with the time spent on consultation), and inclusion of patients in decisions regarding treatment and care is much more limited (as confirmed by 48 patients out of 100).
Although the data illustrate the primary care, one may assume the situation with specialists is not significantly different. The level of intentional medication nonadherence was higher in the group of women.

Moreover, deliberate noncompliance was higher in patients who subjectively perceived the influence of powerful others (e.g. a physician) as lower, and used less emotion-based but more avoidance-based strategies of dealing with stress.

It confirms the intentional and intellectual character of the decision not to use or to minimise pharmacotherapy. With reference to the previously discussed therapeutic relationship it may be assumed that it was unsatisfactory, particularly in the studied group of women. Another potential cause is dissatisfaction with the effects of previous treatment.

Sharma et al. [11] demonstrated that it is a strong predictor of medication nonadherence. In their study $68 \%$ of women with RA were dissatisfied with the effects of treatment, $52 \%$ of all the subjects did not adhere to medical advice, $6 \%$ discontinued therapy completely, and $12 \%$ decided to start alternative treatment.

In the present study the health locus of control was found to be important for medical adherence in RA patients. Attribution of influence to powerful others, e.g. a physician, had a positive effect on medication adherence both in the entire study group and in the group of women. A similar effect was observed in patients with a weaker internal health locus of control. The finding regarding the belief in a positive influence of the physician is consistent with expectations, and reports of other authors [14].

As for the internal health locus of control, we obtained different results, i.e. a negative correlation between the internal health locus of control and medication adherence. Although it is generally assumed that internal health locus of control positively affects health behaviour, the potentially moderating effect of age should be considered.

In our study the median age of subjects was 58 years. According to Rodin [35], with increasing age, variability in preferred amounts of control also increases, and sometimes greater control over activities, circumstances, or health has negative consequences including stress, worry, and self-blame.

We did not observe a correlation between the style of coping with stress and the general level of medication adherence. However, we found that emotion-oriented coping is conducive to unintentional nonadherence, and reduces intentional nonadherence.

The only study in the PubMed database that explores the relationship between coping style and medication adherence in RA patients does not confirm such a correlation; however, Berner et al. [36] used a different tool: the Freiburg Questionnaire for Coping with Illness. 
Although in male subjects with RA the emotionoriented coping style was more often observed than in women, seeking social interaction appeared to be a possible predictor of adherence among men.

This finding is consistent with the results of a study conducted in a group of oncological patients, which confirmed a significant correlation between the level of medication adherence and the use of avoidance-oriented strategies of coping with stress, including the willingness to engage in social relationships [16].

Our study did not reveal a relationship between medication adherence and the level of mindfulness in patients with RA. While no scientific reports examining this type of correlation have been found, numerous studies emphasise the importance of mindfulness for medication adherence in chronic diseases, e.g. heart conditions, HIV [38] or schizophrenia [19]. Following the reports of some authors [38] we confirmed the relationship between medication adherence and age.

Elderly patients appeared to use pharmacotherapy more systematically, which may result from a greater level of adaptation to the disease and its acceptance compared to younger patients, but also from objective factors, such as regular daily routine or more free time.

\section{Limitations of the study}

The present study provides scientific and application insights regarding medication adherence in RA patients; however, it has certain limitations. The analysis of the study groups did not include characteristics such as duration of the disease, intensity of symptoms or the number and severity of comorbidities. It was assumed that during the period of the study the comorbidities were stable. Detailed analysis did not include types of medications used by the subjects, duration or burden of pharmacotherapy.

Therefore, the assessed medication adherence pertained to all the conditions the patient was treated for, not only RA. In the present study we did not analyse whether subjects used any alternative treatment methods or what they might be, although it would be of particular interest with respect to the patients demonstrating intentional nonadherence.

The number of men and women participating in the study was not equal, but it reflects the dominance of women in the general population of patients with RA. Finally, it should be emphasised that, as demonstrated by other authors [31], medication adherence is a dynamic process, and can change in time, similarly to certain psychological characteristics that may evolve spontaneously, due to life experience, or be changed intentionally, as a result of new competences. Therefore, the results of the study do not necessarily reflect a permanent predisposi- tion for medication adherence in a patient with RA, but rather the present situation, a point in the patient's life.

\section{Conclusions}

Our study demonstrated that factors increasing the likelihood of medication adherence in patients with RA include:

- powerful others (e.g. a doctor),

- a low level of internal health locus of control,

- advanced age.

In women, adherence is particularly strongly increased by powerful others, and a low level of internal health locus of control, whereas in men it is increased by seeking social interaction.

We have shown the importance of the belief in the effect of Powerful others, e.g. the attending physician, on the medical adherence in RA patients. It suggests that in this group of patients particular emphasis should be placed on a positive therapeutic relationship, including effective communication, a supporting attitude towards the patient, and education about the validity, use and effects of the prescribed pharmacotherapy.

According to the study results, engagement of the attending physician may have the greatest effect on the medical adherence in women and younger patients, whereas men seeking social interaction appeared to be more willing to adhere to medical advice than women. It indicates that male patients should be motivated to maintain social relationships, both in their community and in support groups for patients with RA.

The authors declare no conflict of interest.

\section{References}

1. Kucharz EJ. Reumatoidalne zapalenie stawów. In: Wielka Interna. Reumatologia. Puszczewicz MJ (ed.). Medical Tribune, Warszawa 2016: 75-88.

2. Kwiatkowska B. Reaktywne zapalenie stawów. In: Reumatologia kliniczna. Zimmermann-Górska I (ed.). Wyd. Lekarskie PZWL, Warszawa 2008: 746-757.

3. Filipowicz-Sosnowska A. Reumatoidalne zapalenie stawów. In: Interna Szczeklika. Podręcznik chorób wewnętrznych. Szczeklik A (ed.). Medycyna Praktyczna, Kraków 2018: 1926-1940.

4. Scott DL, Wolfe F, Huizinga TW. Rheumatoid arthritis. Lancet 2010; 376: 1094-1108, DOI: 10.1016/S0140-6736(10)60826-4.

5. Matcham F, Scott IC, Rayner L, et al. The impact of rheumatoid arthritis on quality-of-life assessed using the SF-36: a systematic review and meta-analysis. Semin Arthritis Rheum 2014; 44: 123-130, DOI: 10.1016/j.semarthrit.2014.05.001.

6. Safiri S, Kolahi AA, Hoy D, et al. Global, regional and national burden of rheumatoid arthritis 1990-2017: a systematic analysis of the Global Burden of Disease study 2017. Ann Rheum Dis 2019; 78: 1463-1471, DOI: 10.1136/annrheumdis-2019-215920. 
7. Batko B, Stajszczyk M, Świerkot J, et al. Prevalence and clinical characteristics of rheumatoid arthritis in Poland: a nationwide study. Arch Med Sci 2019; 15: 134-140, DOI: 10.5114/ aoms.2017.71371.

8. Smolen JS, Landewé R, Breedveld FC, et al. EULAR recommendations for the management of rheumatoid arthritis with synthetic and biological disease-modifying antirheumatic drugs: 2013 update. Ann Rheum Dis 2014; 73: 492-509, DOI: 10.1136/ annrheumdis-2013-204573.

9. Fielis-Giemza A. Strategia leczenia chorych na reumatoidalne zapalenie stawów z uwzględnieniem obecności czynników „złej prognozy". Varia Medica 2017; 1: 92-98 [Published online].

10. van den Bemt BJ, Zwikker HE, van den Ende $\mathrm{CH}$. Medication adherence in patients with rheumatoid arthritis: a critical appraisal of the existing literature. Expert Rev Clin Immunol 2012; 8: 337-351, DOI: 10.1586/eci.12.23.

11. Sharma S, Roshi, Tandon VR, Mahajan A. A Study evaluating adherence and compliance of anti-rheumatic drugs in women suffering from rheumatoid arthritis. J Clin Diagn Res 2015; 9: OC01-OC4, DOI: 10.7860/JCDR/2015/15806.6729.

12. Salt E, Frazier SK. Adherence to disease-modifying antirheumatic drugs in patients with rheumatoid arthritis. Orthopaedic Nursing 2010; 29: 260-275, DOI: 10.1097/ NOR.0b013e3181e5c2c9.

13. Molloy GJ, O'Carroll RE, Ferguson E. Conscientiousness and medication adherence: a meta-analysis. Ann Behav Med 2014; 47: 92-101, DOI: 10.1007/s12160-013-9524-4.

14. Náfrádi L, Nakamoto K, Schulz PJ. Is patient empowerment the key to promote adherence? A systematic review of the relationship between self-efficacy, health locus of control and medication adherence. PLoS One 2017; 12: e0186458, DOI: 10.1371/journal.pone.0186458.

15. Endler NS, Parker JD. Multidimensional assessment of coping: a critical evaluation. J Pers Soc Psychol 1990; 58: 844-854, DOI: 10.1037//0022-3514.58.5.844.

16. Gruszczyńska M, Bąk-Sosnowska M, Szemik S. Selected psychological aspects and medication adherence in oncological patients. Cancer Med 2020; 9: 943-950, DOI: 10.1002/ cam4.2691.

17. Kabat-Zinn J. Full catastrophe living. Nurse Pract 1992, DOI: 10.1097/00006205-199202000-00020 [Published online].

18. Carey MP, Dunne EM, Norris A, et al. Telephone-delivered mindfulness training to promote medication adherence and reduce sexual risk behavior among persons living with HIV: an exploratory clinical trial. AIDS Behav 2020; 24: 1912-1928, DOI: 10.1007/s10461-019-02768-2.

19. Çetin N, Aylaz R. The effect of mindfulness-based psychoeducation on insight and medication adherence of schizophrenia patients. Arch Psychiatr Nurs 2018; 32: 737-744, DOI: 10.1016/ j.apnu.2018.04.011.

20. Brown KW, Ryan RM. The benefits of being present: mindfulness and its role in psychological well-being. J Pers Soc Psychol 2003; 84: 822-848, DOI: 10.1037/0022-3514.84.4.822.

21. Folkman S, Lazarus RS. If it changes it must be a process: study of emotion and coping during three stages of a college examination. J Pers Soc Psychol 1985; 48: 150-170, DOI: 10.1037//0022-3514.48.1.150.

22. Wallston KA, Wallston BS, DeVellis R. Development of the Multidimensional Health Locus of Control (MHLC) Scales.
Health Educ Monogr 1978; 6: 160-170, DOI: 10.1177/109019 817800600107.

23. Culig J, Leppée M. From Morisky to Hill-bone; self-reports scales for measuring adherence to medication. Coll Antropol 2014; 38: 55-62.

24. Toll BA, McKee SA, Martin DJ, et al. Factor structure and validity of the Medication Adherence Questionnaire (MAQ) with cigarette smokers trying to quit. Nicotine Tob Res 2007; 9: 597-605, DOI: 10.1080/14622200701239662.

25. Morisky DE, Ang A, Krousel-Wood M, Ward HJ. Predictive validity of a medication adherence measure in an outpatient setting. J Clin Hypertens (Greenwich) 2008; 10: 348-354, DOI: 10.1111/j.1751-7176.2008.07572.x.

26. Juczyński Z. Narzędzia pomiaru w psychologii zdrowia. Przegląd Psychologiczny 1999; 42: 43-56.

27. Strelau J, Jaworowska A, Wrześniewski K, Szczepaniak P. CISS - Kwestionariusz Radzenia Sobie w Sytuacjach Stresowych. Pracownia Testów Psychologicznych Polskiego Towarzystwa Psychologicznego, Warszawa 2009.

28. Radoń S. Walidacja Skali Świadomej Obecności. Studia Psychologica 2014; 14: 51-70.

29. Brandstetter S, Hertig S, Loss J, et al. 'The lesser of two evils...' - views of persons with rheumatoid arthritis on medication adherence: a qualitative study. Psychol Health 2016; 31: 675692, DOI: 10.1080/08870446.2016.1139111.

30. Prudente LR, Diniz Jde S, Ferreira TX, et al. Medication adherence in patients in treatment for rheumatoid arthritis and systemic lupus erythematosus in a university hospital in Brazil. Patient Prefer Adherence 2016; 10: 863-870, DOI: 10.2147/PPA.S79451.

31. Adina TS, Mihaela-Simona S, Lucia CP, et al. The influence of socio-demographic factors, lifestyle and psychiatric indicators on adherence to treatment of patients with rheumatoid arthritis: a cross-sectional study. Medicina (Kaunas) 2020; 56: 178, DOI: 10.3390/medicina56040178.

32. Clifford S, Barber N, Horne R. Understanding different beliefs held by adherers, unintentional nonadherers, and intentional nonadherers: application of the Necessity-Concerns Framework. J Psychosom Res 2008; 64: 41-46, DOI: 10.1016/j.jpsychores.2007.05.004.

33. Kumar K, Raza K, Gill P, Greenfield S. The impact of using musculoskeletal ultrasound imaging and other influencing factors on medication adherence in patients with rheumatoid arthritis: a qualitative study. Patient Prefer Adherence 2016; 10: 1091-1100, DOI: 10.2147/PPA.S99702.

34. OECD/EU. Health at a Glance: Europe 2018 - State of health in the EU Cycle 2018, DOI: 10.1787/9789264012639-en.

35. Rodin J. Aging and health: effects of the sense of control. Science 1986; 233: 1271-1276, DOI: 10.1126/science.3749877.

36. Berner C, Erlacher L, Fenzl KH, Dorner TE. Medication adherence and coping strategies in patients with rheumatoid arthritis: a cross-sectional study. Int J Rheumatol 2019; 2019: 4709645, DOI: 10.1155/2019/4709645.

37. Salmoirago-Blotcher E, Carey MP. Can mindfulness training improve medication adherence? Integrative review of the current evidence and proposed conceptual model. Explore (NY) 2018; 14: 59-65, DOI: 10.1016/j.explore.2017.09.010.

38. Park DC, Hertzog C, Leventhal $\mathrm{H}$, et al. Medication adherence in rheumatoid arthritis patients: older is wiser. J Am Geriatr Soc 1999; 47: 172-183, DOI: 10.1111/j.1532-5415.1999.tb04575.x. 